Eugenia Kravariti, KING'S COLLEGE LONDON, eugenia.kravariti@kcl.ac.uk Amy Gillespie, UNIVERSITY OF OXFORD,amy.gillespie@psych.ox.ac.uk Kelly Diederen, KING'S COLLEGE LONDON, kelly.diederen@kcl.ac.uk Sophie E. Smart, KING'S COLLEGE LONDON, sophie.smart@kcl.ac.uk Caroline Mayberry, KING'S COLLEGELONDON, caroline.l.mayberry@kcl.ac.uk Alan J. Meehan, KING'S COLLEGELONDON, alan.meehan@kcl.ac.uk Danielle Bream, KING'S COLLEGE LONDON, danielle.bream@kcl.ac.uk Peter Musiat, KING'S COLLEGELONDON, peter.musiat@kcl.ac.uk Silia Vitoratou, KING'S COLLEGELONDON, silia.vitoratou@kcl.ac.uk

Daniel Stahl, KING'S COLLEGE LONDON, daniel.r.stahl@kcl.ac.uk Kyle R. Dyer, KING'S COLLEGE LONDON, kyle.dyer@kcl.ac.uk Sukhwinder S. Shergill, KING'S COLLEGE LONDON, sukhi.shergill@kcl.ac.uk Kelly Coate, UNIVERSITY OF SUSSEX, k.coate@sussex.ac.uk Jenny Yiend, KING'S COLLEGELONDON, jenny.yiend@kcl.ac.uk

\title{
Applying the Higher Education Academy Framework for Partnership in Learning and Teaching in Higher Education to Online Partnership Learning Communities: A Case Study and an Extended Model
}

\section{ABSTRACT}

As internet access and use increase exponentially, pedagogical practice becomes increasingly embedded in online platforms. We report on an online initiative of engaged student learning, the peer-led, staff-assisted e-helpdesk for research methods and statistics, which we evaluated and redeveloped using the lens and guiding principles of the framework for partnership in learning and teaching of the Higher Education Academy (HEA). The aim of the redevelopment was to steer the initiative towards a more integrative and sustainable implementation, as manifest in the applied construct of an online partnership learning community. Our evolving experience of the e-helpdesk highlighted the central role of the facilitator in engineering and maintaining social presence in the online community. We propose an extended model for building an online partnership learning community, whereby partnership encapsulates all the essential elements of student and staff partnership as outlined in the HEA framework, but is also critically defined by similar parameters of partnership between users and facilitators. In this model, the facilitator's role becomes more involved in instructional teaching as disciplinary expertise increases, but descending levels of disciplinary expertise can foster ascending levels of independent learning and shared discovery for both users and facilitators.

\section{KEYWORDS}

Higher Education Academy, online learning community, e-helpdesk, instructional teaching, independent learning 


\section{INTRODUCTION}

Engaging students as partners in learning and teaching in higher education is a sophisticated and effective way of developing student engagement and of improving education (Healey, Flint, \& Harrington, 2014). ${ }^{1}$ Partnership in a pedagogical context refers to a relationship where every partner is "actively engaged in - and stands to benefit from - the process of learning and working together" (Healey et al., 2014, p. 7). In the specific context of higher education, partnership primarily refers to a form of engagement between students and academic staff that "may involve individual staff and students, or between Higher Education Provider ... and students' unions” (Higher Education Academy, 2018). Drawing on theories and evidence that link partnership with positive educational outcomes-enhanced motivation and learning, the development of meta-cognitive awareness, a stronger sense of identity, and improved teaching and classroom experiences (Cook-Sather, Bovill, \& Felten, 2014) — the pedagogical case for staff-student partnership is gaining momentum in recent years. This is reflected in manifestos and initiatives by UK-based, not-for-profit organisations that monitor and advise on the quality of higher education, for example, the National Union of Students, the Quality Assurance Agency, the Higher Education Funding Council for England, and the Higher Education Academy (HEA). The latter has published the Framework for Partnership in Learning and Teaching in Higher Education (Higher Education Academy, 2014), building upon previous literature, such as McMillan and Chavis's (1986) model of "sense of community." The HEA framework provides a conceptual model for partnership, with eight core values (Table 1), as well as four key areas of pedagogical practice in which the partnership becomes invested: learning, teaching and assessment; subject-based research and enquiry; scholarship of learning and teaching; and curriculum design and pedagogic consultancy (Figure 1). Partnership learning communities, in which staff and students engage in a process of learning and inquiry as both scholars and colleagues, are placed at the heart of the model (Figure 1). Partnership learning communities invite critical reflection on existing relationships, identities, processes, and structures, and they can potentially lead to the transformation of the learning experience (Healy et al., 2014). In the communities described by Healy et al., (2014), a strong sense of community is vital for sustaining the partnership, the term emphasising the role of students as active participants in their own and others' education. Importantly, Healy, Flint, and Harrington (2016) highlight a key question that remains largely unexplored: "What are the challenges, opportunities and benefits in developing partnership learning communities?” (Healy et al., 2016, p. 9).

Table 1. The eight core values of the HEA framework for partnership in learning and teaching in higher education HEA CORE VALUES FOR PARTNERSHIP IN LEARNING AND TEACHING IN HIGHER EDUCATION

AUTHENTICITY

All parties have a meaningful rationale for investing in the partnership

All parties are honest about what they can contribute

All parties are honest about the parameters of partnership

Partnership embraces talents, perspectives and experiences from different parties

INCLUSIVITY

There are no structural or cultural barriers preventing potential partners from getting involved

144 Kravariti, E., Gillespie, A., Diederen, K., Smart, S. E., Mayberry, C., Meehan A. J., Bream, D., Musiat, P., Vitoratou, S., Stahl, D., Dyer, K. R., Shergill, S. S., Coate, K., \& Yiend, J. (2018). Applying the Higher Education Academy framework for partnership in learning and teaching in higher education to online partnership learning communities: A case study and an extended model. Teaching \& Learning Inquiry, 6(2). http://dx.doi.org/10.20343/teachlearninqu.6.2.11 


\section{RECIPROCITY}

EMPOWERMENT

TRUST

CHALLENGE

COMMUNITY

RESPONSIBILITY
All parties are interested in, and benefit from working and/or learning in partnership

Power is distributed appropriately

All parties are encouraged to challenge ways of working/learning that reinforce inequalities

All parties take time to get to know each other, and to engage in open and honest dialogue All parties are confident they will be treated with respect and fairness

All parties critique and challenge practices, structures and approaches undermining partnership

All parties are enabled to take risks to develop new ways of working and learning

All parties feel a sense of belonging and are valued fully for the unique contribution they make

All parties share collective responsibility for the aims of the partnership

All parties have individual responsibility for the contribution they make

\section{Figure 1. A conceptual model for students as partners in learning and teaching in higher education (taken from Healey et} al., 2014)

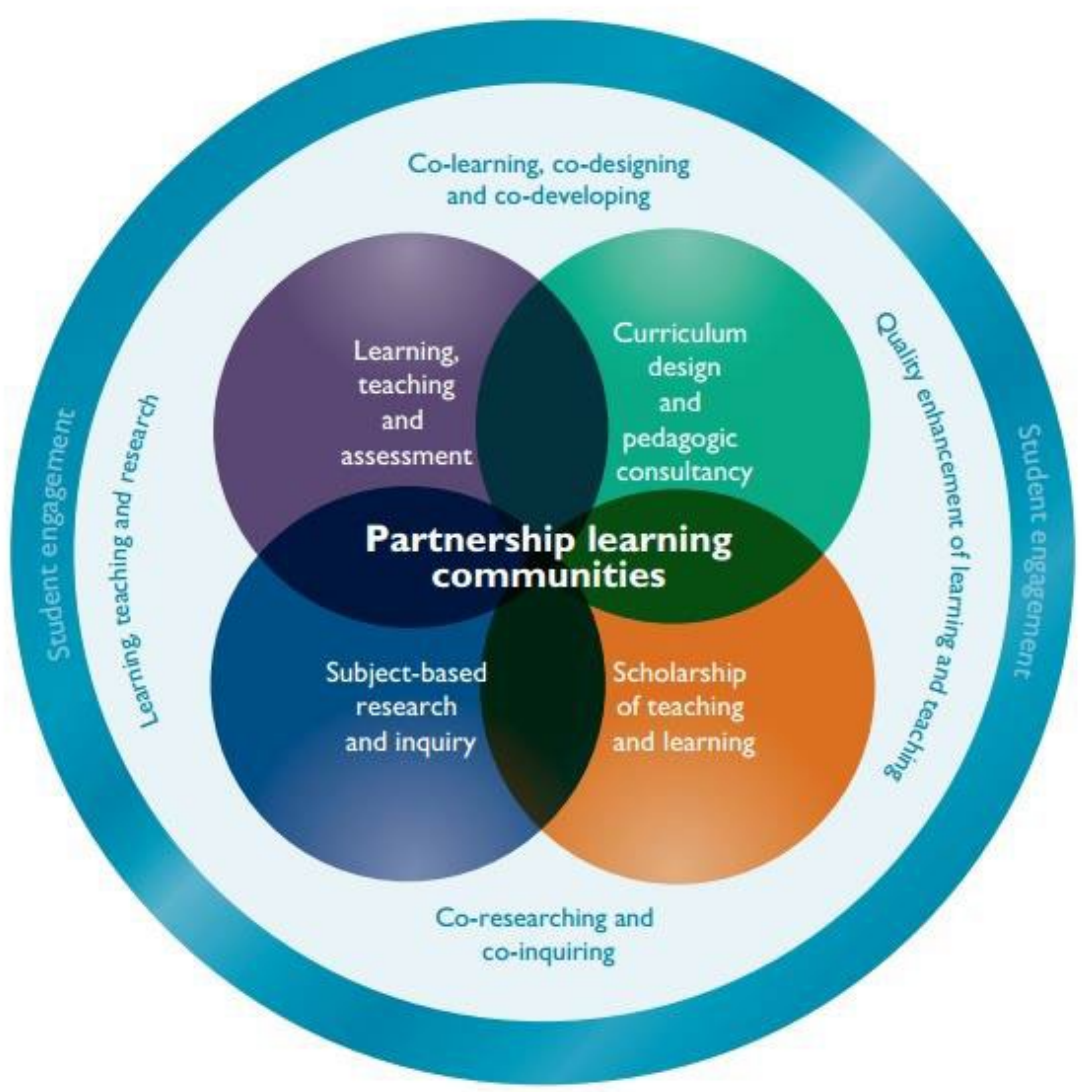




\section{ONLINE LEARNING}

As internet access and use increase exponentially, pedagogical practice becomes increasingly embedded in online learning, creating exciting opportunities. Online learning enhances flexibility and inclusivity by removing the physical barriers of space and time and by increasing the number of students who can choose the "when, where and how" of learning (Song, Singleton, Hill, \& Koh, 2004; Gordon, 2014). New opportunities for experiential learning (Kolb, 1984) emerge, with models such as the flipped or inverse classroom frequently making use of online resources (Gerstein, 2012). The HEA report "Pedagogies of Partnership: What Works" (Crawford, Horsley, Hagyard, \& Derricott, 2015) notes the importance of technology in staff-student partnership, and how being removed from traditional learning environments can provide a novel opportunity for partnership to flourish. However, research also points to challenges, such as frustration with asynchronous communication, students struggling to feel a sense of community, and technical difficulties or structural issues (Song et al., 2004).

Various models of learning have focused on online communities. For example, Garrison, Anderson, and Archer (2000) developed the Community of Inquiry Framework for Online Learning, which describes three essential and interactive elements: cognitive presence, social presence, and teaching presence. This has been used to guide the development of teaching resources, such as one for research design in nursing and midwifery (Mills et al., 2016). Other models have described progressive steps of engaging with online environments (e.g., the five-stage model of e-learning; Salmon, 2000; Salmon, Nie, \& Edirisingha, 2010) or have applied influential educational principles and theories (e.g. situated cognition and Vygotskian thought) to online learning (Hung \& Chen, 2001). However, no previous models of online learning have looked at the concept of partnership learning communities, and no models of partnership learning communities have specifically focused on online learning.

\section{Online partnership learning community}

We report on a collaborative project carried out by students and academic staff (i.e., faculty) at the Institute of Psychiatry, Psychology and Neuroscience-one of nine faculties within King's College London - that provided the opportunity to reflect on the concept of online partnership learning communities.

The project grew out of a pilot initiative in a single postgraduate-taught course, which sought creative ways to engage students with research methods and statistics by using peer learning. Initially, the goal was simply to provide an additional resource to help meet the high student need for learning support in the subject area, which existing resources did not fully address. An online platform was chosen to provide a flexible and accessible space for students who were reluctant to ask questions in the classroom. The success of this small-scale pilot motivated us to look for ways to expand and improve the initiative to reach more students. A commissioned funding call from the HEA in early 2015 provided the opportunity to gain the necessary resources to expand the initiative to a division-wide resource and to evaluate it. The project aligned with one of three strategic enhancement programmes of the HEA (student engagement) and focused on the development of new tools and resources.

As part of the project, the HEA framework for staff-student partnership in learning and teaching in higher education provided an opportunity to reflect on the early phase of the online engaged student learning initiative, and redevelop it (in the section below, A Case Study). In particular, it had become apparent that students rarely engaged with research methods and statistics in an autonomous,

146 Kravariti, E., Gillespie, A., Diederen, K., Smart, S. E., Mayberry, C., Meehan A. J., Bream, D., Musiat, P., Vitoratou, S., Stahl, D., Dyer, K. R., Shergill, S. S., Coate, K., \& Yiend, J. (2018). Applying the Higher Education Academy framework for partnership in learning and teaching in higher education to online partnership learning communities: A case study and an extended model. Teaching \& Learning Inquiry, 6(2). http://dx.doi.org/10.20343/teachlearninqu.6.2.11 
independent, and critical way. Redeveloping the initiative sought to encourage students to become more engaged with both the learning and the teaching of research methods and statistics through a partnership approach. The overall aim of the redevelopment was to steer the initiative towards a more integrative and sustainable implementation, as manifest in the applied construct of an online partnership learning community.

In the final section of this article (An Extended Model), we draw on our reflections and gained insights, on the HEA framework for partnership in learning and teaching in higher education (Higher Education Academy, 2014; Healey et al., 2014), and on the Community of Inquiry Framework for Online Learning (Garrison et al., 2000) to propose an extended model of online partnership learning community with a disciplinary focus.

\section{A CASE STUDY}

In its early phase (before redevelopment), the Faculty-wide, peer-led, staff-assisted Volunteer Electronic Helpdesk for Research Methods and Statistics (e-helpdesk) was an email-based service, run by 18 student and staff volunteers ("facilitators"), who answered questions on research methods and statistics submitted by students ("users"). The initiative adopted an active learning and learning support approach, whereby facilitators self-allocated questions, and worked in pairs to search for answers and formulate responses. Pair allocation assumed equal levels of study or position (e.g., $\mathrm{PhD}$ students with $\mathrm{PhD}$ students, staff with staff), but was otherwise random. Students had the option to triage questions upwards to progressively higher levels of expertise. A volunteer "coordinator" monitored the e-helpdesk for unallocated emails and sent prompts and reminders to the group. All volunteers had access to a private interactive medium within an electronic platform external to the College, where difficult questions could be discussed with the group. The initiative was evaluated by students (Gillespie, Smart, Mayberry, Meehan, Bream) and staff (remaining authors except for Diederen) who used focus groups and interviews with users and facilitators of the e-helpdesk, and with members of the senior institutional and educational management. The student-staff collaboration on evaluating the initiative, from devising the focus group methodology to interpreting the findings to authoring the current paper, helped ensure that any redevelopment was grounded in a process of partnership.

Even in its early phase, the potential for student-staff and student-student partnerships was evident within the initiative. Such potential is highlighted in a brief hypothetical example illustrating the different forms of partnership that could emerge: An MSc student (User) emails the e-helpdesk to inquire about the appropriate statistical test for analysing a dataset. A PhD student (Facilitator A) selfallocates the question and then emails their allocated partner (Facilitator B) to invite collaboration on preparing a response (student-student partnership). The two student facilitators agree upon the correct test but have not used a similar dataset before, so they discuss some aspects of their understanding with a member of staff from the statistics department (Facilitator $\mathrm{C}$ ) via the electronic platform. Together, the three facilitators formulate a draft response (student-staff partnership). Facilitator A remarks that some of the detail Facilitator $\mathrm{C}$ provided is likely to be too advanced for the MSc student. Facilitator A therefore guides the MSc student through the response (student-student partnership, informed by prior student-staff partnership), and this experience enhances Facilitator A's confidence in handling similar questions in the future. 


\section{Evaluation of the e-helpdesk through the prism of the HEA partnership framework}

The focus groups highlighted several examples of good alignment of the e-helpdesk with the core partnership values of the HEA framework (Higher Education Academy, 2014), as well as instances of poor alignment. Selected examples are provided in Table 2, and more detailed accounts with illustrative quotes from the focus groups are appended to the end of the article (Appendix).

Using the HEA partnership framework as a reflective and evaluative tool gave rise to some challenges and occasional resistance from focus group participants. For example, some struggled to draw clear distinctions between concepts such as inclusivity and community, or authenticity and trust. Moreover, the concept of partnership itself was sometimes rejected; for example, some facilitators strongly perceived themselves as "volunteers," were content to receive little in return for their time, and not expecting or desiring an equal or reciprocal relationship. Overall however, reflecting on the alignment of the e-helpdesk with the HEA partnership framework was perceived to be a constructive process that captured significant elements of the e-helpdesk, and therefore helped shape its redevelopment. Our extended reflections on the special considerations surrounding the development and implementation of partnership learning communities in an online context-in relation to the four areas of pedagogical practice and the eight core values of the HEA partnership framework-are summarised in Table 3 (areas of pedagogical practice) and Table 4 (core values).

Table 2. Evaluation of the early phase of the e-helpdesk through the prism of the HEA partnership framework: Examples of good and poor alignment with the core partnership values

\section{EARLY PHASE OF THE E-HELPDESK: ALIGNMENT WITH PARTNERSHIP VALUES}

EXAMPLES OF GOOD ALIGNMENT

EXAMPLES OF POOR ALIGNMENT

\section{AUTHENTICITY}

Participants felt that the nature of the initiative as peer-led and staff-assisted offered an authentic account of the partnerships parameters
Pairing seemed artificial to students, as it was not based on prior relationships

Students felt the arrangement did not create a dynamic context for exchanging ideas and for combining the partners' unique strengths Facilitators felt that the triage system was unhelpful

\section{INCLUSIVITY}

E-helpdesk was perceived as inclusive by ensuring immediate access and convenience of use, and by 'filtering out' social indicators of status and power
Division between two electronic spaces (email account and electronic platform) was perceived as complex and effortful; electronic platform was hardly used

Student facilitators did not readily engage higher levels of expertise

E-helpdesk did not fully embrace perspectives and experiences of each party

148 Kravariti, E., Gillespie, A., Diederen, K., Smart, S. E., Mayberry, C., Meehan A. J., Bream, D., Musiat, P., Vitoratou, S., Stahl, D., Dyer, K. R., Shergill, S. S., Coate, K., \& Yiend, J. (2018). Applying the Higher Education Academy framework for partnership in learning and teaching in higher education to online partnership learning communities: A case study and an extended model. Teaching \& Learning Inquiry, 6(2). http://dx.doi.org/10.20343/teachlearninqu.6.2.11 


\section{RECIPROCITY}

Participants recognised students and staff gained from the partnership and that the e-helpdesk promotes learning for users and facilitators
Some facilitators did not contact their partners, and others did not respond to their partners

\section{EMPOWERMENT}

Seeking help from the e-helpdesk was perceived as empowering users to take charge of their own learning and to gain autonomy and independence
Facilitators did not feel "empowered" to self-allocate or triage questions. Some felt the training did not prepare them to exercise their responsibilities

\section{TRUST}

Users perceived student facilitators as more approachable, less intimidating and judgemental, more understanding and easier to trust than staff
Some users admitted hesitation to trust a source of information or advice that was perceived to lack "professional certification" (i.e., student facilitators)

COMMUNITY

Breaking down the boundaries of physical space and time was seen as "connecting" people and fostering a sense of community
E-helpdesk environment did not enable facilitators and users to project themselves to the group as 'real people." It lacked "social presence"

RESPONSIBILITY

Users and facilitators felt responsible for own and others' learning
Facilitators perceived some other facilitators as completely inactive

Hosting the e-helpdesk in an email account did not promote shared activity, responsibility and accountability, as it was unclear who checked the inbox

Table 3. Engaging with the four areas of pedagogical practice in online partnership learning communities (PLCs) AREAS OF PEDAGOGICAL PRACIICE IN ONLINE PLCS

LEARNING, TEACHING, AND ASSESSING

Students can "translate” explanations given by staff in a particularly organised and coherent way online; facilitators can read and edit each other's explanations, before transmitting to user

Online PLCS provide a convenient way for students to engage in assessment; submissions can be uploaded, anonymised, and assessment provided through online discussion or document comments

\section{SCHOLARSHIP OF TEACHING AND LEARNING}

Records of interactions within online PLCs provide fertile ground for research regarding online educational experiences, especially if the platform supports learning analytics (data on how learners use learning environments)

Online PLCs can provide an alternative environment for conducting educational research and recruiting members of the community as participants. Research can address areas of need indicated by the community 


\section{SUBJECT- BASED RESEARCH INQUIRY}

With research articles increasingly published online, online PLCs are well placed for discussion and critical engagement

Online facilitator roles require critical academic research skills (literature review), or iteratively forming content in collaboration with other academics

Online PLCs enable discussion of proposed research, methodology, analysis, and interpretation, which allows more student supervision

\section{CURRICULUM DESIGN \& PEDAGOGIC CONSULTANCY}

Discussion threads, collaborative documents and videos can form content to engage with and learn from. Partnership creates curriculum in a very real way

Online PLCs can serve as a dynamic feedback system - highlighting subject areas in which users request support, or groups of students who show heightened need-informing curriculum and educational provision development The community can develop in response to need, with an online PLC, therefore embodying both "student voice" and "student change makers"

Table 4. Applying the HEA partnership values to an online learning and teaching community

\section{PARTNERSHIP VALUES}

\section{AUTHENTICITY}

Convenience and flexibility allow all parties to benefit from the partnership from a location and time of their choosing, providing the meaningful rationale for engagement that is critical for authenticity

Online PLCs can have freely available static information providing honest accounts of the community's working arrangements, allowing for explicit communication about partnership terms (Little, Locke, Scesa \& Williams, 2011)

\section{RECIPROCITY}

All parties benefit from online PLCs, e.g., by increasing opportunities for facilitators to receive specific feedback on whether learners are grasping concepts and understanding explanations

Staff address problems without waiting until the next class or end of term; students develop new teaching skills, enhancing their learning

\section{INCLUSIVITY}

"Technologies can be particularly effective ... where finding the time and place for meetings may be impractical... and impossible for part-time or distance learning” (Gordon, 2014, p. 14)

The number of people who can access and contribute to the community increases, bringing together a wider range of skills and perspectives, enhancing cognitive presence (Garrison, 2007)

Technologies can create barriers e.g. for students with visual impairments or no internet access

\section{CHALLENGE}

While open dialogue between facilitators helps build trust and more dynamic discussions, online communities also allow for anonymised surveys to provide critique without respondents fearing repercussion or social difficulties As every communication is stored electronically, facilitators can look back on and reflect upon specific interactions, helping to evaluate whether 
Facilitators quickly access multiple staff and students for support via, e.g., forum posts; others can respond at their convenience

\section{TRUST}

High quality interactions are essential for a cohesive community (McMillan \& Chavis, 1986); people feel safer disclosing online, which stimulates high quality relationships (Valkenburg \& Peter, 2009). Online communication allows more frequent interactions and trust

A subcommunity for facilitators-e.g., separate forum-allows facilitators to support and get to know each other, and discuss the best way to provide disciplinary support (increasing teaching quality)

\section{RESPONSIBILITY}

Individuals may feel their online identity is detached from their usual identity; which can make community members shirk responsibility and disregard social protocol

Unique profiles linked to real identities build a strong sense of individual responsibility, and are essential for social presence (Garrison et al., 2000), avoiding negative effects of anonymous communication (Valkenburg \& Peter, 2009).

As online communication lacks the visibility and physical presence experienced in person, contributions can be missed or members can remain silent. Assigning some facilitators responsibility for monitoring the community ensures it runs smoothly. Open forum encourages participation as contributions are public and visible they are working towards, or undermining, partnership

\section{EMPOWERMENT}

As differences between staff and students become less visible online there is a certain equality with which everyone accesses the community and expresses themselves through the same means. A written post can be evaluated on its own merits, empowering individuals to contribute to and challenge the community.

Incorporating facilitators with certain levels of expertise (not necessarily the most senior staff) is important. When structured appropriately, this empowers facilitators to take on more challenging responsibilities

\section{COMMUNITY}

Building a community online poses unique challenges (e.g., concepts of identities), but also provides unique benefits, namely increased inclusivity and flexibility, allowing a broader range of contributions and interactions Online communities can help maintain and strengthen the relationships between students and staff in between face-to-face interactions

Online communities have the combined advantage of being relatively unrestricted and allowing high levels of inclusivity; this creates the potential to dramatically expand their remit based on need and participation. The storage of all previous interactions allows an ever-growing depository of learning resources that can be passed on to future members.

\section{The redevelopment of the e-helpdesk}

The evaluation of the initial implementation of the e-helpdesk provided a balanced account of the educational potential of the resource, but also of the challenges and unmet needs that limited 
its impact, appeal, rewarding value, and sense of community, which were essential to its function and success. As with the evaluation, the students' involvement in re-developing the e-helpdesk was substantial. On a par with academic staff, and sometimes taking the lead, students decided on the sections and subsections to include in the new virtual environment of the e-helpdesk, co-designed the content of the platform, and took up most of the core coordinator and facilitator roles in the emerging online partnership learning community. The process of redevelopment relied on regular face-to-face meetings between students and staff, who co-decided the direction and implementation of the redevelopment, drawing on the team's gained insights, experience and recommendations during evaluating and reflecting on the early phase of the e-helpdesk.

In setting out to gradually transform the e-helpdesk from an engaged student learning initiative to an online partnership learning community, it was necessary to rethink its structures, processes and working arrangements. One of the most compelling insights gained from the focus groups was that the electronic space of the e-helpdesk (dedicated email account) was self-limiting in scope. While serving the function of a peer-led, staff-assisted service, it did not address the social needs of a learning community. In response to this challenge, the e-helpdesk was integrated into King's E-learning and Teaching Service (KEATS), the College's Virtual Learning Environment, in the form of a module, which integrated four core functions: The original email account (for users who prefer a more "private" setting for learning support), a public discussion forum open to all students and staff in theFaculty, a private discussion forum for the exclusive use of the facilitators, and a depository of learning support resources for research methods and statistics. Retaining the original email application aimed to increase inclusivity, as not all users would feel comfortable or confident to post a question on a public forum (for example, if they thought their question was "silly" or too basic). At the same time, allowing users to post anonymously on the forum would take away from the sense of community that we wanted to build. The module and all its functions were readily accessible using the College members' personal King's College London log-in details, thus removing the barrier of multiple electronic spaces and login details.

To integrate the educational dimension of the e-helpdesk with the social aspect of a partnership learning community, we created facilitator profiles on the KEATS module, including each volunteer's photograph (a black-and-white picture containing a gold star), level of study or academic position, background, experience, skills and expertise. The varied aspects of the volunteers' roles were outlined in clear role descriptions (three main categories were created: "coordinators," who see to the running and continual development of the e-helpdesk; "e-moderators," who monitor, moderate, and build social presence, cognitive presence and understanding in the public forum; and "investigators," who engage in subject-based inquiry, draft responses, and provide constructive feedback to other investigators). All students and staff at the Institute of Psychiatry, Psychology \& Neuroscience were invited to enroll on and use the e-helpdesk. Whereas all users were welcome to initiate and participate in discussion threads, only the $\mathrm{PhD}$ student facilitators were formally obliged to respond to queries. All $\mathrm{PhD}$ student facilitators were selected on the basis of their experience and expertise in statistical analysis. The student facilitators received tailored training for their role, and were assisted by the module leaders and other academic staff members, who acted in an advisory capacity. The various role descriptions, each containing essential and optional elements, defined a minimum of responsibility for the volunteers. Having defined minimum expectations struck a balance between allowing flexibility, creating a sustainable e-helpdesk, and encouraging honesty

152 Kravariti, E., Gillespie, A., Diederen, K., Smart, S. E., Mayberry, C., Meehan A. J., Bream, D., Musiat, P., Vitoratou, S., Stahl, D., Dyer, K. R., Shergill, S. S., Coate, K., \& Yiend, J. (2018). Applying the Higher Education Academy framework for partnership in learning and teaching in higher education to online partnership learning communities: A case study and an extended model. Teaching \& Learning Inquiry, 6(2). http://dx.doi.org/10.20343/teachlearninqu.6.2.11 
about commitment. However, a great deal of emphasis was placed on a range of provisional roles the volunteers could opt for, depending on their own motivation and time commitments.

To engage the whole team of facilitators in collaborative work, submissions to the email account and to the public forum were moved to the private forum by the coordinator and e-moderators. Automatic email notifications from the private forum alerted the facilitator team to new posts, which were directly accessible through a link in the email notification. Investigators were charged with the tasks of drafting, rating, commenting on, and approving draft responses. The final approved response was posted on the forum or emailed to the user. The minimum requirement attached to the investigator role was rating the draft responses of fellow facilitators and commenting on the clarity and accessibility of responses. Using the private forum enabled volunteers to receive help, positive feedback and appreciation for their work. The private forum also ensured a consistent quality of responses, and gave all volunteers, whether investigators or not, a chance to contribute to the construction of an answer. Finally, a professional statistician handled the most difficult of queries, which other volunteers were not confident to address.

A final focus of the redevelopment was to integrate the e-helpdesk with the four areas of partnership and to promote sustainability. Sections entitled "Volunteer for the Helpdesk," "Give Us Feedback," "What Useful Topics are missing from Your Curriculum?," "How Can Teaching and Learning Support Get Better?," "Complete Our Questionnaire," and "Ideas for Educational Research" gathered information and opinions that helped strengthen the links between the e-helpdesk and quality enhancements in teaching and learning in the Faculty (Institute of Psychiatry, Psychology \& Neuroscience). Coordinators were given responsibility for monitoring submissions and making recommendations to the programme leaders' fora about areas for improvement and curriculum development. The section "Complete Our Questionnaire" provided links to surveys from ongoing educational projects to promote scholarship of teaching and learning. One of the links was to the O-PaL questionnaire (Meehan \& Bream, 2015), which was designed by our team to evaluate online partnership learning initiatives in terms of their alignment with the HEA framework and impact on individual and institutional levels. Throughout this final focus of redevelopment, we realised that the definition of "user" - initially restrained to students submitting questions on research methods and statistics - could be expanded drastically. Not only could the e-helpdesk module be used by staff who sought to further their knowledge of research methods and statistics, but a "user" could include anyone who used the online community as a source of information or feedback, including senior staff that accessed the forum with the aim of gaining ideas for curriculum development. The KEATS e-helpdesk module was launched in late 2015 and is still ongoing currently, in April 2018.

\section{Partnerships in the redeveloped e-helpdesk}

There are considerably more forms of partnership evident within the redeveloped ehelpdesk, and "partnership" is salient to its description: Users are informed that the e-helpdesk volunteers will "work as learning partners with you" (student-student or student-staff partnerships), and the e-helpdesk is described as student-led and staff-supported, with volunteers "putting their heads together" to provide support (student-student or student-staff partnership). We can explore these partnerships by revisiting the previous hypothetical example of a question about the appropriate statistical test: In the redeveloped ehelpdesk, it could be a staff member (a user) who poses the question within the forum, wishing to develop a more advanced level of understanding 
before setting some reading for a module he or she co-ordinates. A PhD student e-moderator responds quickly, welcoming them (building an initial staff-student partnership). A combination of $\mathrm{PhD}$ students and academic staff members discuss the question within the private forum, bringing varying forms of expertise (staff-student partnerships). The final response is relayed to the original user, the staff member, by an e-moderator (continuing the staff-student partnership). An MSc student user comes across this post two weeks later and discusses the response with a PhD student e-moderator, who helps draw out the key messages and promotes shared understanding (student-student partnership). A staff member user from another department notices the post while browsing the forum two months later, and comments that he has frequently struggled to obtain good resources to support the understanding of the particular statistical test discussed. A combination of staff and student users, as well as academic staff members, provides suggestions and recommendations, and a co-ordinator feeds back at the programme leaders' fora (network of staff-student partnerships) to inform the development of curricula, resources, and library services within the Faculty (Institute of Psychiatry, Psychology \& Neuroscience).

\section{AN EXTENDED MODEL}

The case study illustrates that the HEA framework of partnership in learning and teaching in higher education provides a useful tool for evaluating and redeveloping online partnership learning and teaching initiatives. Using the framework as a theoretical "compass," the e-helpdesk as an experiential "anchor," and the focus groups as a dialectic platform, we were able to identify a number of factors that suggested a mismatch between the e-helpdesk and the applied construct of a partnership learning community.

Most of the challenges that limited the successful application of the partnership values to our online initiative could be subsumed under two overriding stumbling blocks: The electronic platform (email application) and the narrow conceptualisation of the role of the facilitator. The limited functionalities of the email application were adequate for a question and answer service, but not for the complex needs of a partnership learning community. The email medium did not allow effective group interaction as it lacked the convenience of easy access and automatic email notifications, it reduced accountability, and it confined the benefits of the e-helpdesk to individuals who directly engaged with the cognitive activities of the e-helpdesk.

A more important consideration is the definition of the facilitator's role in the initial implementation of the e-helpdesk. This included cognitive parameters but lacked aspects that could purposefully and dynamically help build and sustain a "social presence" in the online environment. As defined in the Community of Inquiry Framework for Online Learning (Garrison et al., 2000), social presence includes the ability to project one's personal characteristics into the online community (i.e., present oneself as a "real person"), express feelings in relation to the educational experience (e.g., exchange humorous remarks or disclose personal information), and communicate openly with fellow members (e.g., direct a comment to someone in particular, openly express appreciation and agreement, or compliment and encourage others; Garrison et al., 2000). By lacking social presence, the e-helpdesk also lacked group cohesion, described as "focused collaborative communication that builds participation and empathy" (Garrison et al., 2000).

While offline communities can rely on their members to engage in spontaneous social interactions, online environments rely on the symbolic representation of social presence, which does

154 Kravariti, E., Gillespie, A., Diederen, K., Smart, S. E., Mayberry, C., Meehan A. J., Bream, D., Musiat, P., Vitoratou, S., Stahl, D., Dyer, K. R., Shergill, S. S., Coate, K., \& Yiend, J. (2018). Applying the Higher Education Academy framework for partnership in learning and teaching in higher education to online partnership learning communities: A case study and an extended model. Teaching \& Learning Inquiry, 6(2). http://dx.doi.org/10.20343/teachlearninqu.6.2.11 
not arise automatically. Therefore, the role of the facilitator is central to engineering and sustaining social presence in the online partnership learning community and needs to be defined and implemented using social (in addition to cognitive and teaching) indicators (Garrison et al., 2000; Swan \& Shea, 2005). Recent studies on the development of a "sense of virtual community" highlight that online moderation and development of social norms has a significant impact on engagement with and within a virtual community (Carey \& Meyer, 2016), and that users experience a stronger sense of learning community when instructors show a stronger teaching presence (Shea, 2006). Based on the above observations, we propose an extended model of an online partnership learning community, whereby partnership encapsulates all the essential elements of student and staff partnership, as outlined in the HEA framework, but is also critically defined by similar parameters of partnership between users and facilitators (Figure 2). In this extended model, members of the learning community fall anywhere on (and can move across) the four groups formed by the "students-staff" and "users_facilitators" categories of the partnership, each of which is essential for the community; this was reflected in the redeveloped e-helpdesk, in which both students and staff could act as both users and facilitators. Disassociating the role of "user" from students and acknowledging that any member of the community can fall anywhere within these categories allows staff-student partnership to be truly inclusive, reciprocal and empowering. It also acknowledges that staff-student partnership rarely occurs in isolation from student-student and staff-staff partnerships, particularly within a learning community.

In the Community of Inquiry Framework for Online Learning (Garrison et al., 2000), social presence interacts with two other essential elements: cognitive presence and teaching presence. Cognitive presence represents a cycle of puzzlement, subject-based inquiry, search for meaning, and problem resolution, which broadly represents the nature of cognitive transactions between users and facilitators in the e-helpdesk. However, the initial implementation of the e-helpdesk provided limited opportunity for fostering a teaching presence, both because students were reluctant to triage questions to higher levels of expertise and the activities of the e-helpdesk and the role of the student facilitator were narrowly defined. In the Community of Inquiry Framework for Online Learning (Garrison et al., 2000), teaching presence includes instructional management (e.g., setting curriculum, designing methods and assessment, establishing time parameters), building understanding (e.g., facilitating an educational transaction, drawing in less active participants, acknowledging individual contributions, reinforcing appropriate contributions, and focusing discussion), and direct instruction (e.g., facilitating reflection and discourse, presenting content, asking questions, proactively guiding and summarising the discussion, confirming understanding through assessment and feedback, and providing constructive explanatory feedback).

Online partnership learning communities should provide flexibility and inclusivity in the way students and staff, as users and facilitators of the partnership learning community, engage with the essential elements of social, cognitive, and teaching presence. The respective indicators should formally be integrated in the facilitator role, giving all members the opportunity to facilitate at whichever level is most beneficial for themselves and the users. At the most basic level, everybody can contribute to the social presence of the community. At an intermediate level, users and facilitators engage with educational transactions that express a cognitive presence and focus on building understanding. Combined with social presence, this intermediate level broadly corresponds to the activities of the redeveloped e-helpdesk, where the focus and content of the educational transaction is defined by the needs and interests of the users (puzzlement). At a higher level of

Kravariti, E., Gillespie, A., Diederen, K., Smart, S. E., Mayberry, C., Meehan A. J., Bream, D., Musiat, P., 
integration with formal curricula, facilitators engage with direct instruction and instructional management. This level corresponds with the future phase of development of the e-helpdesk, where the initiative dynamically evolves and expands to offer an e-space for recreating, reinforcing and consolidating formal teaching activities in the department (e.g., online modules managed instructionally by a module leader with the help of student facilitators). We have visually represented these reflections in Figure 3, where opportunities and/or confidence to facilitate at the levels of direct instruction and instructional management increase with increasing disciplinary and/or teaching expertise, but descending levels of disciplinary expertise can foster ascending levels of independent learning, shared discovery and transformative learning for both users and facilitators.

Figure 2: Extending the Higher Education Academy framework in the context of online partnership learning communities. Partnerships include student-student, staff-staff, student-staff, user-user, facilitator-facilitator and user-facilitator

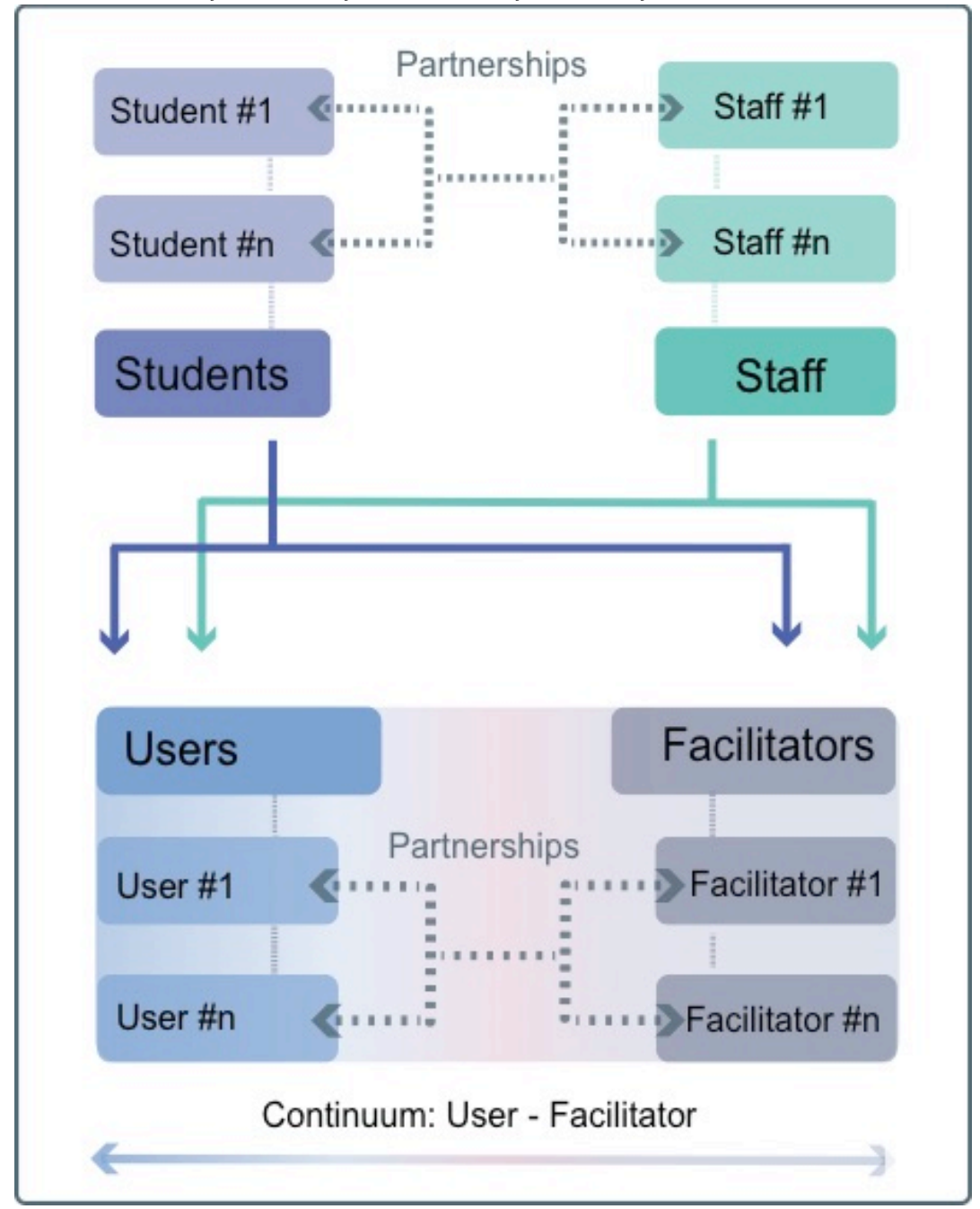


Figure 3: A partnership template inspired by the framework for partnership in learning and teaching in higher education (Higher Education Academy, 2014) and by the Community of Inquiry Framework for Online Learning (Garrison et al., 2000)
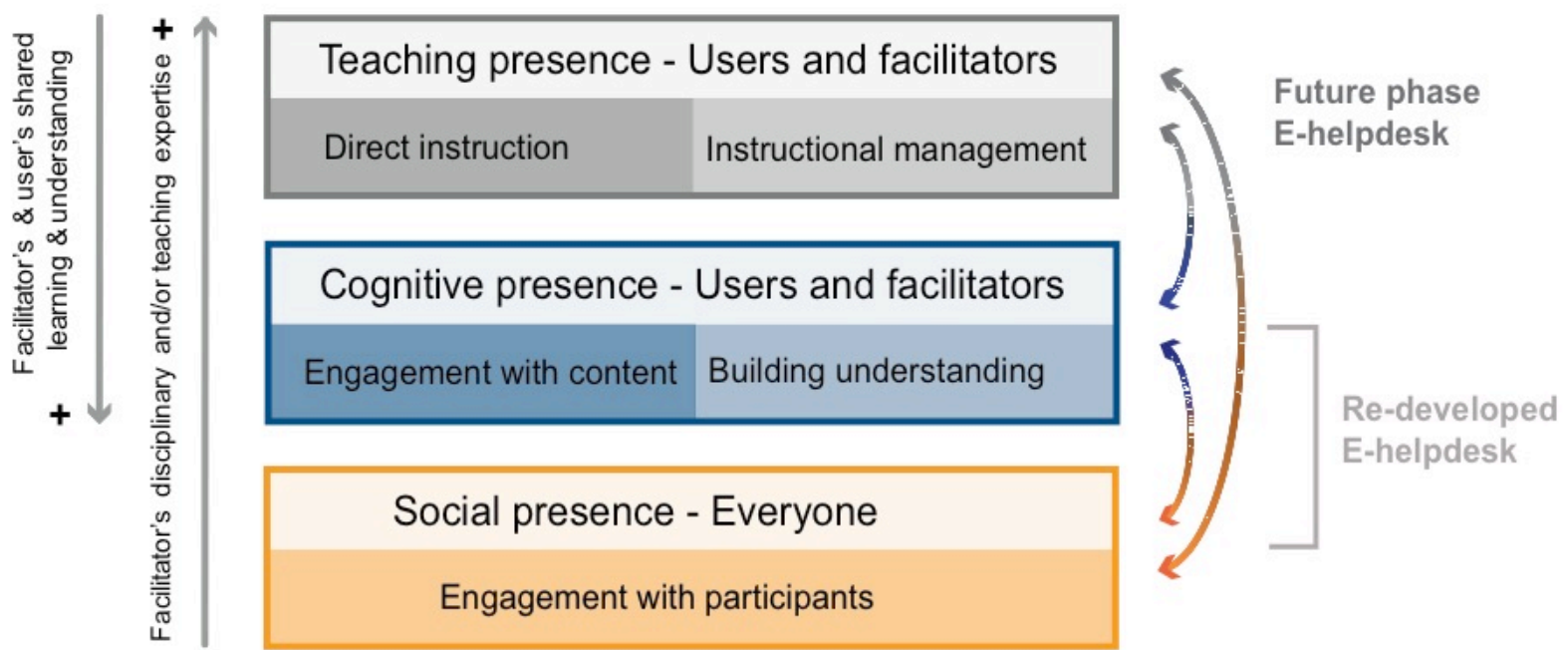

\section{CONCLUSION}

The HEA framework of partnership in learning and teaching in higher education provides a useful tool for evaluating and redeveloping online partnership learning and teaching initiatives. Our own initiative highlighted the central role of the facilitator in engineering and maintaining social presence in the online partnership learning community. In our extended model, partnership encapsulates all the essential elements of student and staff partnership, as outlined in the HEA framework, but is also critically defined by similar parameters of partnership between users and facilitators. As disciplinary expertise increases, the facilitator's role becomes more involved in instructional teaching, and as it decreases, independent learning and shared discovery increase for both users and facilitators.

While we are optimistic about the future of our redeveloped initiative, ongoing reflection on some of the prominent challenges we faced is important. Maintaining a sense of community and responsibility in an online context is particularly challenging. While an enhanced focus on social presence has aided cohesion, difficulties in this key area remain (as Mills et al., 2016 also found), highlighting a need for further exploration. More generally, balancing authenticity with inclusivity when developing partnership learning communities with a disciplinary focus is challenging, because specific disciplinary knowledge and expertise is so greatly valued and relied upon that other contributions can be undervalued. While expanding and refining our definition of facilitator has worked to address this difficulty, further exploration of this key area within discipline-specific partnership communities is essential. Practically, a future challenge for us will be to consider how (or if) our initiative, developed within one department for a specific pedagogical purpose, could have a broader impact on the educational culture of partnership between staff and students across an 
institution as large as King's College London. As an online community on a university-wide e-learning platform, the potential may be greater than for other communities; but that is yet to be seen.

\section{ACKNOWLEDGMENTS}

The current work received funding support by the Higher Education Academy. This article would have not been possible without the contributions of all students and staff who took part in our focus groups and interviews. Their input and insights form the backbone of our work.

Eugenia Kravariti is a Senior Lecturer at King's College London (UK). Eugenia works in the Psychosis Studies department and is a Programme Leader for an MSc in Mental Health Studies. Her primary research interests include neuropsychology of psychosis.

Amy Gillespie is a Postdoctoral Researcher at the University of Oxford (UK). Amy was a PhD student and Graduate Teaching Assistant at King's College London while this research was carried out. Her primary research interest is psychopharmacology.

Kelly Diederen is a Lecturer at the Department of Psychosis Studies at King's College London (UK). Kelly is a module and co-module leader for an MSc in Mental Health Studies and Psychiatric Research and she supports an MSc in Early Interventions in Psychosis.

Sophie E. Smart is a PhD student and Research Worker at King's College London (UK). Sophie has worked as a Graduate Teaching Assistant, and her primary research interest is prediction response to antipsychotics.

Caroline Mayberry was an MSc student at King's College London (UK). Caroline completed her MSc in Addiction Studies and is now working as a Public Relations and Marketing Account Manager, focusing in international education clients.

Alan J. Meehan is a Postdoctoral Research Associate at the Social, Genetic \& Development Psychiatry Centre, King's College London (UK). Alan was a PhD student and a Graduate Teaching Assistant while this research was being carried you're his primary research interest is developmental pathways to psychiatric disorder.

Danielle Bream was an MSc student at King's College London (UK). She completed her MSc in Neuroscience in 2015.

Peter Musiat is a Postdoctoral Researcher at King's College London (UK). Peter works in the Department of Psychological Medicine, His primary research interest is e-platforms for mental health care.

Silia Vitoratou is a Lecturer in Psychometrics at King's College London (UK). Silia works in the Biostatistics and Health Informatics department and leads the Psychometrics and Measurement Lab.

Daniel Stahl is a Professor in Medical Statistics and Statistical Learning at King's College London (UK). Daniel works in the Biostatistics and Health Informatics department, is Lead of the Precision Medicine and Statistical Learning Group, Lead Trial Statistician, and Education Lead for the department.

Kyle R. Dyer is a Reader in Distance Learning in Mental Health at King's College London (UK). Kyle is the Director of Distance Learning, Academic Lead for Online Education, and Chair of the KCL Massive Open Online Course Strategy Committee.

Sukhwinder S. Shergill is a Professor in Psychiatry and Systems Neuroscience at King's College London (UK). Sukhi also leads the Cognition, Schizophrenia and Imaging Laboratory, and is a Consultant Psychiatrist at the Maudsley Hospital.

158 Kravariti, E., Gillespie, A., Diederen, K., Smart, S. E., Mayberry, C., Meehan A. J., Bream, D., Musiat, P., Vitoratou, S., Stahl, D., Dyer, K. R., Shergill, S. S., Coate, K., \& Yiend, J. (2018). Applying the Higher Education Academy framework for partnership in learning and teaching in higher education to online partnership learning communities: A case study and an extended model. Teaching \& Learning Inquiry, 6(2). http://dx.doi.org/10.20343/teachlearninqu.6.2.11 
Kelly Coate is Professor of Higher Education and Pro Vice Chancellor for Education and Students at the University of Sussex (UK). Kelly was formerly Vice Dean of Education for the Faculty of Social Science and Public Policy at King's College London and Director of the King's Learning Institute while this research was carried out.

Jenny Yiend is a Reader in Cognitive Psychopathology and Head of Graduate Studies (Taught) at King's College London (UK). Her research interests include cognitive and emotional processing in mental health.

\section{NOTE}

1. Eugenia Kravariti, Amy Gillespie, Kelly Diederen, and Sophie Smart contributed equally to this manuscript and are joint first authors.

\section{REFERENCES}

Carey, M. C., \& Meyer, H. K. (2016). The influences of participation and moderation on the development of a sense of virtual community. International Journal of Web Based Communities, 12(4), 326-341. https://doi.org/10.1504/IJWBC.2016.080812

Cook-Sather, A., Bovill, C., \& Felten, P. (2014). Engaging Students as Partners in Teaching and Learning: A Guide for Faculty. San Francisco: Jossey-Bass.

Crawford, K., Horsley, R., Hagyard, A., \& Derricott, D. (2015). Pedagogies of Partnership: What Works. York: Higher Education Academy. Retrieved from https://www.heacademy.ac.uk/resource/pedagogiespartnershipwhat-works\#sthash.10215C3W.dpuf

Garrison, D. R. (2007). Online community of inquiry review: Social, cognitive, and teaching presence issues. Journal of Asynchronous Learning Networks, 11(1), 61-72.

Garrison, D. R., Anderson, T., \& Archer, W. (2000). Critical inquiry in a text-based environment: Computer conferencing in higher education model. Internet and Higher Education, 2(2-3), 87-105. http://dx.doi.org/10.1016/S1096-7516(00)00016-6

Gerstein, J. (2012). The flipped classroom model: The full picture for higher education. Retrieved from https://usergeneratededucation.wordpress.com/2012/05/15/flipped-classroom-the-full-picture-forhigher-education/

Gordon, N. (2014). Flexible Pedagogies: Technology-Enhanced Learning. York: Higher Education Academy.

Healey, M., Flint, A., \& Harrington, K. (2014). Engagement Through Partnership: Students as Partners in Learning and Teaching in Higher Education. York: Higher Education Academy.

Healey, M., Flint, A., \& Harrington, K. (2016). Students as partners: Reflections on a conceptual model. Teaching \& Learning Inquiry, 4(2), 1-13. https://doi.org/10.20343/teachlearninqu.4.2.3

Higher Education Academy (2014). Framework for Partnership in Learning and Teaching in Higher Education. York: Higher Education Academy. Retrieved from https://www.heacademy.ac.uk/system/files/resources/hea framework for partnership in learning and teaching.pdf

Higher Education Academy (2018). Student Engagement Through Partnership in Higher Education. York: Higher Education Academy. Retrieved from https://www.heacademy.ac.uk/individuals/strategicpriorities/student-engagement

Hung, D. W., \& Chen, D. T. (2001). Situated cognition, Vygotskian thought and learning from the communities of practice perspective: Implications for the design of Web-based e-learning. Educational Media International, 38(1), 3-12. https://doi.org/10.1080/09523980121818

Kolb, D. A. (1984). Experiential Learning: Experience as a Source of Learning and Development. Englewood Cliffs: Prentice Hall.

Little, B., Locke, W., Scesa, A., \& Williams, R. (2009). Report to HEFCE on Student Engagement. Bristol: HEFCE. Retrieved from http://www.hefce.ac.uk/pubs/rereports/year/2009/studentengagement/.

McMillan, D. W., \& Chavis, D. M. (1986). Sense of community: A definition and theory. Journal of Community Psychology, 14(1), 6-23.https://doi.org/10.1002/1520-6629(198601)14:1\%3C6::AIDJCOP2290140103\%3E3.0.CO;2-I 
Mills, J., Yates, K., Harrison, H., Woods, C., Chamberlain-Salaun, J., Trueman, S., \& Hitchins, M. (2016). Using a community of inquiry framework to teach a nursing and midwifery research subject: An evaluative study. Nurse Education Today, 43(August), 34-39. https://doi.org/10.1016/j.nedt.2016.04.016

Salmon, G. K. (2000). E-Moderating: The Key to Teaching and Learning Online. New York: Routledge.

Salmon, G., Nie, M., \& Edirisingha, P. (2010). Developing a five-stage model of learning in Second Life. Educational Research, 52(2), 169-182.https://doi.org/10.1080/00131881.2010.482744

Shea, P. (2006). A study of students' sense of learning community in online environments. Journal of Asynchronous Learning Networks, 10(1), 35-44. Retrieved from https://onlinelearningconsortium.org/read/journal-issues/

Song, L., Singleton, E. S., Hill, J. R., \& Koh, M. H. (2004). Improving online learning: Student perceptions of useful and challenging characteristics. Internet and Higher Education, 7(1), 59-70. Retrieved from https://www.learntechlib.org/p/102596/

Swan, K., \& P. Shea. Social Presence and the Development of Virtual Learning Communities. In: S. Hiltz and R. Goldman (Eds.), Learning Together Online: Research on Asynchronous Learning Networks (pp. 239260). Mahwah: Lawrence Erlbaum, 2005.

Valkenburg, P. M., \& Peter, J. (2009). The effects of instant messaging on the quality of adolescents' existing friendships: A longitudinal study. Journal of Communication, 59(1), 79-97. https://doi.org/10.1111/j.1460$\underline{2466.2008 .01405 . x}$

\section{APPENDIX}

\section{Appendix 1: Did the initial implementation of the e-helpdesk embody the partnership values?}

\section{Authenticity}

Examples of alignment with the framework

Participants felt that acknowledging the nature of the initiative as peer-led and staff-assisted offered an authentic account of the parameters of the partnership.

Steve (user): It won't be a problem to say that they are students, as long as there is some indication that there are staff as well, there is staff as well.

\section{Inclusivity}

By ensuring immediate access and convenience of use, and by "filtering out" social indicators of status and power, the e-helpdesk was perceived as inclusive.

Marie (user): I think it will help a lot, because for a person that lives really far away... there's no need to travel up.

Chairperson: Do you think having an online helpdesk reduces the barriers that might come up from kind of things to do with like gender, class, ethnicity, anything like that?

Marie (user): It generally helps. Yes.

Sandy (user): Definitely.

\section{Reciprocity}

Participants recognised that both students and staff stand to gain from the partnership, and that the helpdesk promotes disciplinary learning for both users and facilitators (although more so for users).

Emily (user): Yes, because if the MSc student wasn't... like 100\% sure about the answer, they could check it with the staff... 
Chairperson (facilitator): And do you think there's a situation where you think the staff member can benefit from running it by students, or PhD by an MSc student?

Emily (user): Student . . . explanation. You know staff explain things and you just think "I still don't get what you're talking about!", so with a student maybe they'll be able to kind of simplify the language a little bit.

Chairperson: How would you feel about kind of working in a partnership with someone you're emailing...? Emily (user): Yeah, that would be good...

Adam (facilitator): I suppose the idea is for both to learn, but the person asking the question is obviously going to get more from it because they asked the question, they need to know this for some reason. Whereas you obviously are going to learn something and it's going to contribute to your overall knowledge ... but you're not going to have the same weight attached to the information as the person is.

\section{Empowerment}

Taking the initiative to address one's difficulties by actively seeking help from the e-helpdesk was perceived as empowering users to take charge of their own learning and to gain autonomy and independence.

Lilly (user): I think the e-helpdesk maybe helps the user feel a bit more ... a sense of . . autonomy, because then they're feeling like "Oh yeah, I'm being more independent with my statistics research". I'm not always having to bother like either other people on my course or my supervisor because you don't always want to go to your supervisor and be like "Oh I don't quite understand how I should interpret this analysis" or something like that. So then it helps you feel more independent.

\section{Trust}

Users perceived student facilitators as more approachable, less intimidating and judgemental, and more understanding than staff, and therefore easier to trust.

Frank (user): [P] eople probably find it easier to ... ask your fellow students as opposed to going to an academic for example...

Sally (user): It's probably actually more encouraging to know that it's not going to be necessarily an expert that's going to like, judge your silly questions, and [will be] somebody that's going to understand it as well. Steve (user): On the contrary, I think that with a student you can have a bit more, you know, direct communication, because you're not afraid of saying something that is 'stupid' or anything. And a student is in your shoes as well so you can have that support alongside the information.

\section{Challenge}

The helpdesk was seen as a novel paradigm of partnership, which challenged traditional forms of teaching in the faculty.

Lilly (user): I think that's unique to the e-helpdesk and it just shows... how they're integrating, like, student and staff learning.

Dunya (facilitator): And my course uses different lecturers for every lecture because they're specialists in their field apparently. So you can't have a partnership with like sixty different lecturers, because you just can't. 


\section{Community}

Breaking down the boundaries of physical space and time was seen as "connecting" people, as fostering a sense of community.

Marie (user): [O]nline help is ... its making him feel like always connected and always online....

Because something like that I think really benefits the community sense.

\section{Responsibility}

Users and facilitators felt responsible for their learning and that of their fellow students.

Chairperson: It's also getting that balance between giving an answer and being helpful. And telling them what to do or taking too much control over it. ... So yeah, it's just getting that balance between helping without over-helping.

Emily (user): I think it's kind of important that you don't just give someone the answer.... And you might not learn from the answer if you're just like "Ok that's the answer" and copying the statement.

\section{Examples of poor alignment with the framework \\ Authenticity}

Students perceived the pairing arrangement as artificial and unhelpful, because it was not based on an established relationship. They also felt that it did not create a dynamic context for exchanging ideas, and for combining the partners' unique strengths: experience (staff) and relatable, accessible terms of communication (students). Furthermore, facilitators did not like the triage system. As such, they lacked a meaningful rationale for investing in these aspects of partnership.

Cathy (facilitator): See, I felt ... like a Masters student being paired with a PhD student might be more beneficial. Or at least for the Masters student [when paired with each other] ... there's two of us together who have the same level of expertise... then if we see a question that neither of us know, neither of us are going to attempt to answer it. Whereas if there's one partner... not so much that they would have to 'carry the team'... I don't want to have to feel that way, but there could be more of a learning thing with each other.

Natalie (facilitator): And there was this whole talk about ... a hierarchy, and [that] if MSc students don't know, they should take it to a PhD and if the PhD [doesn't know], it should go to a staff [member]. And I didn't like that.

\section{Inclusivity}

The activities of the helpdesk were divided between two electronic spaces (email account for "serial" communication between facilitators and users; external electronic platform for "group" interaction). These required different log-in details and lacked the convenience of email notifications. The arrangement was perceived as complex and effortful and the external electronic platform was hardly used. Student facilitators did not readily engage higher levels of expertise (triage questions). The structural barriers of the electronic platform and the low success of the triage system translated into narrow use of the available expertise. The unidimensional definition of the facilitator role in rigid learning and teaching terms further suggested that the helpdesk did not sufficiently embrace the different talents, perspectives and experiences of all parties. 
Cathy (facilitator): It seemed like just a lot of information because we're kind of going on just a lot of different websites. So we have the email that's for the helpdesk, then you have the [electronic interactive medium] that's just so detached from it, and then, you know, the information that was separate about the training and whatever.

Nancy (facilitator): I logged in once, made an account and then I've forgotten about it since.

Natalie (facilitator): Because it's not notification-based, it's just another thing to check and it's ... it's just hard.

\section{Reciprocity}

Some facilitators did not contact their partners, and others did not respond to their partners.

Adam (facilitator): And then I think I have never actually got in touch with my partner personally. And it's just like "Hello! Hi ... We're here to like, bounce things off each other..." Never did that-oops!

Dunya (facilitator): See I did. I emailed my partner and I said ... "Hi I'm ..." introduced myself, "Do you think it would be good... I will send you an email to say 'Oh will you have a look at my reply?'” and it took her about a month to get back to me. And when I did email her, because I had written a reply, I just never heard back from her.

\section{Empowerment}

The facilitators were given the power to decide whether to self-allocate or triage questions. However, due to the challenges discussed above, they were not "empowered" in their role. In addition, some felt that the training they had received did not match their needs and, as a result, they were unsure about how to go about their responsibilities.

Nancy (facilitator): Yeah, I came back [from training] and I just ... I felt really like "Oh, I don't know what I'm doing". I mean I thought like they sent out the slides so ... and then they sent out the recording, but it was so quick. Even the recording... I was like ok so I understand, I've listened to what other people have done, but I still don't really feel like... I feel like it could have been more in-depth. But I don't know how you would train someone to do it because everyone is different.

\section{Trust}

Although users trusted that they will be treated with respect and understanding by student facilitators (more so than staff who might have lower tolerance for "silly" questions), some admitted hesitation to trust a source of information or advice that was perceived to lack "professional certification."

Steph (user): I don't know. I wouldn't completely trust a student because ... honestly I . . I did five universities overall and I remember when I had some questions, some problems. Other university forums, all this kind of stuff, and loads of times I got wrong answers. Loads of times, even from PhD students or even from system professors! I don't know ... I would like... it's an amazing thing that everyone can help, but ... if I see that my reply... my answer I get comes from a student, I would check with my supervisor just to be sure. I'm not saying that I wouldn't take it ... just to be sure.

\section{Challenge}

By inviting all stakeholders of the helpdesk to participate in focus groups, all parties were encouraged to constructively critique and challenge practices, structures and approaches that undermine partnership. 
However, this was a one-off for the evaluation. The team felt that a continuous mechanism for feedback should be integrated in the helpdesk.

Nancy (facilitator): I think this [focus group] is the most useful thing I think I've been to about the helpdesk. Just hearing what other people's experiences are and thinking "Ok mine are similar".

\section{Community}

In addition to posing structural barriers to "team work" (electronic platform), the helpdesk environment did not enable facilitators and users to project themselves to the group as "real people." It lacked the binding element of "social presence." The helpdesk lacked a sense of community.

Samantha (facilitator): Do you feel the facilitators are a team or not? Because I'm getting the slight impression not!

Natalie (facilitator): I don't know anyone's names.

\section{Responsibility}

The facilitators voiced concerns about the different levels of commitment and engagement among the wider facilitator team, with some members being perceived as completely inactive. In addition, the lack of awareness about who was checking the email inbox highlighted the fact that hosting the helpdesk in an email account did not promote shared activity, responsibility and accountability.

Nancy (facilitator): And we have no idea how and when people are checking so some people may not be checking at all, and other people might be helping really frequently. So there's just no idea.

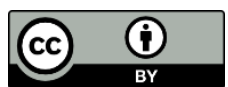

Copyright for the content of articles published in Teaching \& Learning Inquiry resides with the authors, and copyright for the publication layout resides with the journal. These copyright holders have agreed that this article should be available on open access under a Creative Commons Attribution License 4.0 International (https://creativecommons.org/licenses/by/4.0). The only constraint on reproduction and distribution, and the only role for copyright in this domain, should be to give authors control over the integrity of their work and the right to be properly acknowledged and cited, and to cite Teaching \& Learning Inquiry as the original place of publication. Readers are free to share these materials-as long as appropriate credit is given, a link to the license is provided, and any changes are indicated. 